\title{
A qualidade de vida no trabalho e sua relação com a produtividade e lucratividade de uma empresa de serviço de pequeno porte
}

\author{
The quality of work life and its relationship with the productivity and \\ profitability of a small service company
}

\begin{abstract}
Recebimento: 17/03/2021 - Aceite: 24/04/2021 - Publicação: 01/09/2021 Processo de Avaliação: Double Blind Review
\end{abstract}

\author{
Maria Lúcia Gili Massi \\ Doutora em Letras Clássicas pela USP (Universidade de São Paulo) \\ FIPEN (Instituto Paulista de Ensino), Brasil \\ mgilimassi@gmail.com \\ https://orcid.org/0000-0003-2740-6409
}

\author{
Lucas Augusto Alexandre Camargo ${ }^{1}$ \\ Graduando em Administração de Empresas \\ FIPEN (Faculdade Instituto Paulista de Ensino), Brasil \\ lucasaugusto1721@ hotmail.com \\ http://orcid.org/0000-0002-1442-0407
}

\section{RESUMO}

A Qualidade de Vida no Trabalho tem sido considerada um agente impulsor da vantagem competitiva das organizações. Sua implantação promove um ambiente de trabalho mais desenvolvido e prazeroso aos empregados, que respondem com aumento de produtividade e lucratividade, levando a empresa a atuar no ciclo de sucesso, pois há uma sintonia entre o bem-estar do empregado e o êxito financeiro da empresa. Com esse enfoque, este estudo, baseado em pesquisas bibliográficas e de campo, se propõe a verificar se a produtividade e lucratividade de uma pequena empresa de serviço são consequência do investimento que ela faz em programas de QVT, oferecendo, aos empregados, planos de carreiras, remuneração compatível com o mercado, incentivo ao desenvolvimento das competências, 'empoderamento', autonomia e outras práticas que, conforme a teoria, colocariam as organizações de serviço no ciclo de excelência. Os resultados mostraram que a produtividade e lucratividade da empresa pesquisada não são consequência exclusiva do investimento em programas de QVT, pois a empresa tem apenas uma ação de qualidade de vida e o ambiente de trabalho não é saudável, no entanto, suas margens de lucratividade e

\footnotetext{
${ }^{1}$ Bolsista de Iniciação Científica apoiado pelo Conselho Nacional de Desenvolvimento Científico e Tecnológico - CNPq - Brasil.
} 


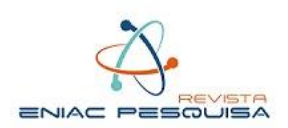

produtividade são médias, quando deveriam ser baixas, demonstrando, com isso, que há outras variáveis interferindo nesse processo.

Palavras chave: ciclo do fracasso, ciclo da mediocridade, ciclo do sucesso, programas de qualidade de vida no trabalho, lucratividade

\begin{abstract}
The Quality of Life at Work has been considered an agent that drives the competitive advantage of organizations. Its implementation promotes a more developed and pleasant work environment for employees, who respond with increased productivity and profitability, leading the company to operate in the success cycle, as there is a harmony between the employee's well-being and the company's financial success. With this focus, this study, based on bibliographic and field research, aims to verify whether the productivity and profitability of a small service company are a consequence of the investment it makes in QVT programs, offering employees career plans. , remuneration compatible with the market, incentive for the development of skills, empowerment, autonomy and other practices that, according to theory, would put service organizations in the cycle of excellence. The results showed that the productivity and profitability of the researched company are not the exclusive consequence of the investment in QVT programs, since the company has only one quality of life action and the working environment is not healthy, however, its profitability and profit margins. productivity are medium, when they should be low, thus demonstrating that there are other variables interfering in this process.
\end{abstract}

Keyword: failure cycle, cycle of mediocrity, success cycle, quality of life at work programs, profitability

\title{
1. INTRODUÇÃO:
}

A literatura revela que há relação entre a manutenção de programas Qualidade de Vida no Trabalho (QVT) e os ciclos de desempenho das empresas, que são classificados em: fracasso, mediocridade e sucesso (Lovelock, Wirtz, Hemzo, 2011). Identificar e descrever tais ciclos permite que sejam tomadas medidas para modificar as práticas condutoras ao fracasso e à mediocridade, de modo a alcançar o nível de excelência nas organizações.

No mercado concorrido em que estão inseridas, as empresas de um modo geral, incluídas as de serviço de pequeno porte, devem continuamente ajustar as suas práticas ao 
ciclo de sucesso, a fim de alcançar a produtividade e a lucratividade que garantam a sua sobrevivência (Macedo, 2012).

Lovelock e outros (2011) apontam as ações que compõem cada ciclo de atuação das empresas, dizendo que há uma sintonia entre o bem-estar ou mal-estar do empregado, a satisfação ou insatisfação do cliente e a consequente lucratividade da empresa. Tais ações se traduzem em práticas de gestão de pessoas, que devem estar presentes no contexto contemporâneo, envolvendo os processos de atração, movimentação, desenvolvimento, orientação e cuidado com as pessoas (Dutra, Dutra e Dutra, 2017).

Entretanto, ainda que sejam recomendados vários planos de desenvolvimento, orientação e cuidado com as pessoas para que as empresas alcancem o ciclo do êxito, há estudos mostrando que a maioria das pequenas empresas pouco investem nessas técnicas (Massi, Pereira, Santana, Gonçalves, Souza, Silva e Silva, 2010). Normalmente, elas operam estimulando os empregados a serem dependentes dos procedimentos, das descrições de cargos, e outras práticas mecanicistas. Geralmente, não incentivam e nem valorizam a independência dos empregados, dando-lhes poder e autonomia (Serva, 1997).

Por isso, estagnadas, muitas pequenas empresas acham-se no ciclo do fracasso ou da mediocridade, e os seus gestores encontram-se numa bolha, abatidos, e não conseguem sair desse lugar. $\mathrm{O}$ contato com tal realidade e o conhecimento das teorias inspirou a elaboração deste estudo, que pretende responder ao problema de pesquisa seguinte: há correlação entre o oferecimento de programas de QVT, os ciclos de gestão e os níveis de produtividade e lucratividade de uma empresa de serviço?

A importância deste estudo, para o meio empresarial, reside em cogitar caminhos para a sobrevivência de pequenas empresas. Para o meio acadêmico, justifica-se a pesquisa porque mostra os resultados de uma observação no lugar, apresentando a realidade, em termos de gestão de pessoas, de uma pequena empresa da Grande São Paulo.

Apoiado nas fontes de pesquisas, o presente estudo se propõe a verificar se a produtividade e lucratividade de uma pequena empresa de serviço, localizada na Grande São Paulo, são consequência do investimento que ela faz em programas de QVT, oferecendo, aos empregados, planos de carreiras, remuneração compatível com o mercado, incentivo ao desenvolvimento das competências, empoderamento, autonomia e outras 


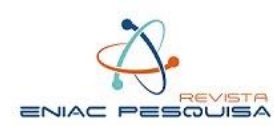

práticas que, conforme a teoria, colocariam as organizações de serviço no ciclo de sucesso/excelência.

Este artigo está dividido em sete seções, sendo esta Introdução, a primeira. Na seção 2, será apresentada a Fundamentação Teórica. Em seguida, será descrita, na seção 3, a Metodologia. Na quarta seção, serão apresentados os Resultados e Discussão. Na quinta seção, serão feitas as Considerações Finais. Na sexta seção, estão os Agradecimentos, e, na última seção, Referências, estão as fontes de consulta.

\section{FUNDAMENTAÇÃO TEÓRICA}

As organizações de serviço, dependendo da forma pela qual gerem seus empregados da linha de frente - os que mantêm contato direto com os clientes, podem, como resultado decorrente desse gerenciamento, atuar em um destes três ciclos: fracasso, mediocridade e sucesso (Lovelock e outros, 2011).

Os resultados esperados por uma organização são decorrentes de determinados fatores que formam a ideia de produtividade. Para Reggiani, Prada e Figueiredo (2005), o conceito de produtividade vem associado à maneira como são utilizados os recursos na produção de um bem ou serviço.

Produtividade é um dos processos mais impactantes na sobrevivência de uma empresa no concorrido mundo contemporâneo. Essa concorrência faz com que inúmeras empresas se reorganizem para serem mais competitivas no mercado. Para Macedo (2012), a gestão da produtividade vem se tornando cada vez mais crucial em um ambiente de globalização dos negócios. Hoje, sem produtividade ou sem a eficiência do processo produtivo, dificilmente uma empresa será bem-sucedida ou sobreviverá.

No Brasil, a abertura econômica, a partir de 1990, que expôs as empresas brasileiras a um ambiente de grande competição; a estabilização da moeda, e a evolução do cidadão brasileiro, enquanto consumidor, que passou a exercer mais plenamente seus direitos e deveres, foram fatores indutores e decisivos para a gestão da produtividade nas organizações (Lobo, 2003).

Para Machline (1985), a nova realidade tornou competitivas as empresas mais flexíveis que, rapidamente, se adaptaram ao novo contexto, ampliando o domínio sobre o 
processo produtivo, com redução dos desperdícios, aumento dos níveis de produtividade e integração da mão de obra ao processo produtivo. Contudo, Macedo (2012), diz que outros recursos produtivos, não tangíveis, devem ser considerados, e, dentre eles, cita: a gestão, a cultura organizacional e o conhecimento.

As empresas têm por finalidade o lucro e, para se obter o lucro, a produtividade e a redução dos custos de produção contribuem para a lucratividade das empresas (Martins, 2006). Para Sink e Tutle, 1993, o lucro é o resultado da receita sobre os custos de produção.

Se a forma de gerenciamento é um dos recursos produtivos (Martins, 2006), que contribuem para a lucratividade das empresas, desperta a curiosidade investigar a possível correlação existente entre o oferecimento de programas de QVT, os níveis de produtividade, as margens de lucro e os indícios dos ciclos de fracasso, mediocridade e sucesso/excelência das empresas. A Tabela 1, a seguir, mostra uma correlação viável entre essas variáveis.

Tabela 1 - Correlação entre os níveis de produtividade, de lucratividade e os ciclos de gestão das empresas.

\begin{tabular}{|c|c|c|c|}
\hline Ciclos: & Fracasso & Mediocridade & Sucesso/Excelência \\
\hline \multirow[t]{2}{*}{ Produtividade } & Baixa & Média & Alta \\
\hline & $\begin{array}{l}\text { Tarefas repetitivas. } \\
\text { Controle na mão do chefe. } \\
\text { Alta rotatividade dos } \\
\text { funcionários. } \\
\text { Baixa qualidade nos serviços. } \\
\text { Tarefas que exigem pouco } \\
\text { treinamento. }\end{array}$ & $\begin{array}{l}\text { Não há grandes cobranças } \\
\text { para a produtividade. } \\
\text { Funcionários sobem de cargo } \\
\text { e ganham aumentos por tempo } \\
\text { de serviço, não por méritos. } \\
\text { Desempenho medido pela } \\
\text { ausência de erros. } \\
\text { Excesso de burocracia. }\end{array}$ & $\begin{array}{l}\text { Fidelização e } \\
\text { retenção de clientes } \\
\text { devido à satisfação } \\
\text { dos funcionários. } \\
\text { Superior qualidade } \\
\text { dos trabalhos e do } \\
\text { atendimento ao } \\
\text { cliente. }\end{array}$ \\
\hline \multirow[t]{2}{*}{ Lucratividade } & Baixas margens de lucro & Margens de lucro médias & $\begin{array}{l}\text { Altas margens de } \\
\text { lucro }\end{array}$ \\
\hline & $\begin{array}{l}\text { Altos custos de substituição e } \\
\text { treinamento de novos } \\
\text { funcionários. } \\
\text { Empregados mal pagos. } \\
\text { Altos investimentos em } \\
\text { marketing e propaganda. } \\
\text { Foco na atração de clientes } \\
\text { novos. } \\
\text { Grandes descontos para atrair } \\
\text { novos clientes. }\end{array}$ & $\begin{array}{l}\text { Baixa ou nenhuma } \\
\text { lucratividade, podendo até dar } \\
\text { prejuízos (como em alguns } \\
\text { monopólios estatais); }\end{array}$ & $\begin{array}{l}\text { Foco na fidelização } \\
\text { do cliente, pois reter } \\
\text { é muito mais } \\
\text { lucrativo do que } \\
\text { atrair. }\end{array}$ \\
\hline
\end{tabular}

Fonte: os autores 
O ciclo do fracasso ocorre quando os empregados da linha de frente trabalham sob pressão, são mal remunerados e facilmente substituíveis, sentem-se subutilizados e consideram-se tratados como pequenas engrenagens de um sistema. Esse ambiente provoca alta rotatividade, e, além disso, muitos empregados insatisfeitos transferem a insatisfação para os clientes, afugentando-os e manchando a imagem da empresa para o público em geral (Santana e Gosling, 2017). As empresas de telemarketing são exemplos (Lovelock e outros, 2011). Como o lucro dessas empresas é comprimido a uma pequena margem, elas, interessadas em obter lucro maior, se instalam no ciclo do fracasso, mantendo baixo o custo da mão de obra (Lovelock e outros, 2011). A baixa complexidade do trabalho, impacta sobre o requisito de acesso dos empregados, que é mínimo. O treinamento oferecido se restringe à operação do serviço, e, o tempo médio de permanência dos empregados na empresa é de 18 meses (Dutra e outros, 2017). Nesse tipo de organização, o poder é depositado nas mãos dos chefes, que não permitem aos subordinados liberdade para criar fora das rotinas (Rocha e Guilhon, 2019).

A busca por lucratividade move acionistas e diretores a coagirem os chefes a tirarem o máximo rendimento dos empregados, pressionando-os na execução dos trabalhos. Devido as constantes pressões por resultados, a frustração enfrentada no cargo e a baixa remuneração, os empregados sentem-se desmotivados e, muitos, sabotam a empresa, transferindo o descontentamento ao atender o cliente (Lovelock e outros 2011).

Desmotivados são também os empregados que atuam nas empresas estacionadas no ciclo da mediocridade, baseado na impossibilidade de abertura às novas ideias. Nessas organizações, os empregados, para não cometer erros, são doutrinados a seguir rígidas e complexas normas de conduta que bloqueiam a flexibilidade para inovar (Schenatto e Lezana (2001).

O ciclo da mediocridade ocorre, sobretudo, em grandes cartéis e em muitas organizações públicas, onde, na maioria das vezes, os servidores concursados gozam da estabilidade. Em muitas dessas empresas, qualquer que seja o desempenho, os empregados sobem de cargos ou obtém aumentos na remuneração pelo tempo de casa (Lovelock e outros, 2011). Schenatto e Lezana (2001) dizem que a isonomia salarial imprime nos servidores uma inércia na mediocridade. Nesse ambiente, os profissionais mais capacitados e motivados são encorajados a se acomodar, pela falta de incentivo e recompensa por seus 


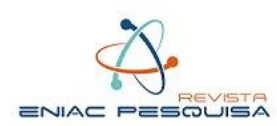

méritos, ou pela pressão dos demais em manter o status quo, que garante o acordo implícito baseado na "lei do menor esforço" (Schenatto e Lezana, 2001).

Com esse enredo, torna-se fácil identificar o sentimento dos consumidores e usuários dos serviços. Obrigados a agir de acordo com manuais e regras, a maioria dos funcionários desenvolve um trabalho medíocre, muito aquém do esperado. Para Fernandes, Rosito, Teixeira, Mota, Patrício, Moraes e Kiorsak (2006) há, nessas organizações, um "pacto da mediocridade": os funcionários fingem que trabalham e se dedicam ao extremo; os gerentes fingem que administram e, sobretudo, controlam, e todos fingem que se importam, como prioridade, com os clientes. Para esses autores, os principais problemas dessa gestão são: a) falta de individuação; b) a maior parte dos gerentes administra baseado na ideia de desempenho médio, gerando insatisfação e desmotivação nos mais dedicados; c) sem a valorização e o reconhecimento dos talentos e esforços individuais não podem ser formadas grandes equipes de trabalho; d) a atuação profissional é limitada ao estritamente necessário, não havendo como construir uma grande organização. Empresas calcadas em regras rígidas, engendram funcionários desmotivados, que geram clientes descontentes criando um círculo vicioso (Fernandes e outros, 2006).

Caminhando em sentido contrário ao traçado nos parágrafos precedentes, muitas empresas estão adotando novos estilos de gestão centrados nas pessoas, vistas como um dos seus bens mais preciosos (Monteiro, Martins, Alves e Paulista, 2015). O mesmo acontece nas organizações de serviço, que escolheram agir no ciclo do sucesso ou da excelência, permanecendo cada vez mais atentas aos anseios dos empregados. Nessa direção, Lovelock e outros (2011) mencionam que por trás da maioria das organizações de serviços bem-sucedidas está o sério compromisso delas com a gestão eficaz dos seus recursos humanos.

Nessas organizações, os planos de gestão de pessoas são projetados a longo prazo, porque sabem que medidas visando o curto período não surtem bons resultados. Nelas, há programas de QVT, mediante boas remunerações, colaboradores bem treinados, bem tratados, 'empoderados', com liberdade para agir, sempre incentivados a disseminar e implementar novas ideias apoiadas pelo líder e pela empresa por meio de recursos colocados à disposição. Nessas organizações, os empregados sentem-se importantes, apresentam um rendimento muito melhor e produzem melhores resultados ao 
transformarem ideias em produtos ou serviços bem-sucedidos junto ao cliente (Lovelock e outros, 2011).

Segundo Kliksberg (1992), os fatores primordiais para uma empresa alcançar o ciclo do sucesso são: a) o enriquecimento do trabalho; b) a participação; c) existência dos grupos de qualidade; d) transparência; e) difusão sistemática de informação sobre o desempenho da organização; f) revisão permanente da política de remuneração; g) conversão do treinamento em política integral; h) priorização do desenvolvimento do potencial humano; i) manutenção da moral do trabalho, e j) características da cultura corporativa. Os empregados das empresas que atuam com esses princípios, satisfeitos com o tratamento que recebem, produzem serviços de qualidade, cativando e gerando a fidelização do cliente, que indica a empresa para outros, mesmo quando o preço é maior do que o dos concorrentes. Fidelização, com melhores margens, são elementos importantes em tempos de alta concorrência, que, junto com colaboradores contentes e clientes satisfeitos, criam o ciclo do sucesso, tornando a empresa lucrativa e referência para outras (Alves e Lins, 2013).

Ambientes de trabalho ruins traduzem-se, costumeiramente, em serviços pavorosos, com empregados que tratam clientes como são tratados por seus gestores (Lovelock e outros, 2011). Se os empregados da linha de frente são tratados com os elementos da racionalidade instrumental (Guerreiro-Ramos, 1981, como citado em Serva, 1997, p. 19), que vê o homem como instrumento de produção e de obtenção do lucro, o ciclo do fracasso se instala, mas, se o indivíduo é tratado com os elementos da racionalidade substantiva (Guerreiro-Ramos, 1981, como citado em Serva, 1997, p. 19), que vê o homem como protagonista das suas entregas, a participação humana é valorizada, e o ciclo de excelência se estabelece. Empresas que oferecem segurança no emprego, mas pouco espaço para iniciativas pessoais, passam pelo ciclo da mediocridade (Lovelock e outros, 2011).

Há uma sintonia entre o cuidado com os empregados, ou seja, a Qualidade de Vida no Trabalho (QVT), e os ciclos de atuação das empresas. O conceito de QVT, historicamente mais associado à saúde e a segurança, pode ser entendido como a orientação gerencial baseada nas expectativas e necessidades dos empregados (Limongi-França e Kanikadan, 2006). Para a professora Limongi-França (2007, como citado em Equipe FIA da Pesquisa Melhores Empresas, 2019), os indicadores de Qualidade de Vida no Trabalho 


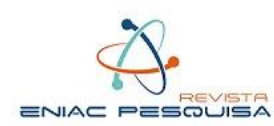

podem ser enquadrados nas dimensões: organizacional; biológica; psicológica e social. A dimensão biológica está ligada à saúde e segurança no trabalho, ao controle de riscos ergonômicos, ambulatório médico, ginástica laboral, refeições e saúde. A dimensão psicológica refere-se à condução dos processos de recrutamento e seleção, avaliação de desempenho, perspectivas de carreira, salário, vida pessoal, camaradagem, clima de trabalho, realização pessoal: a empresa deve valorizar seus empregados, designar desafios e oferecer sistemas de participação, para que se sintam motivados. A dimensão social está relacionada à confiança e responsabilidade: a organização deve proporcionar treinamentos para as equipes, incentivar o equilíbrio entre o tempo dedicado ao trabalho e o tempo dedicado à família e aos amigos. A dimensão organizacional diz respeito à imagem da empresa, inovação e tecnologia, ausência de burocracia e rotinas, tempo livre para os empregados, cuidado com os filhos, desenvolvimento de competências, estilos de liderança, dentre outros (Arellano e Limongi-França, 2013).

Para Sucesso (1998), a QVT abrange: a) renda capaz de satisfazer às expectativas pessoais e sociais; b) orgulho pelo trabalho realizado; c) vida emocional satisfatória; d) autoestima; e) imagem da empresa junto à opinião pública; f) equilíbrio entre trabalho e lazer; g) horários e condições de trabalho sensatos; h) oportunidades e perspectivas de carreira; i) uso do potencial; j) respeito aos direitos; e k) justiça nas recompensas.

A QVT implica profundo respeito com as pessoas e contribui para que as organizações promovam um cuidado com os empregados, e, consequentemente, com a instalação e manutenção do ciclo de sucesso, pois, investindo no capital humano, as empresas investem nelas mesmas, alcançando metas maiores, níveis elevados de qualidade, aumento de produtividade e lucros crescentes (Lovelock e outros 2011).

Pesquisas empíricas mostram que as empresas que implantaram programas de QVT tiveram diminuição dos índices de turnover e de absenteísmo (Arellano e Limongi-França, 2013).

Baseado no quadro teórico apresentado, este estudo se propõe a verificar se a produtividade e lucratividade de uma pequena empresa de serviço, localizada na Grande São Paulo, são consequência do investimento que ela faz em programas de QVT, oferecendo, aos empregados, planos de carreiras, remuneração compatível com o mercado, incentivo ao desenvolvimento das competências, empoderamento, autonomia e outras 
práticas que, conforme a teoria, colocariam as organizações de serviço no ciclo de sucesso/excelência.

\section{METODOLOGIA}

O quadro teórico, feito com base em pesquisas bibliográficas, ofereceu material para elaboração de um instrumento, que serviu de roteiro para observação das ações de QVT utilizadas na empresa pesquisada. O instrumento de coletada de dados, Apêndice A, consistiu de informações para caracterização da empresa e de um questionário com trinta e uma práticas de QVT, que são práticas de gestão enquadradas nos elementos da racionalidade substantiva, com possibilidade de respostas Sim ou Não.

A observação foi feita em abril de 2020, e, o observador é um dos autores deste trabalho que é Gerente de uma das duas lojas.

\section{RESULTADOS E DISCUSSÃO}

A pesquisa de campo foi feita em uma empresa de pequeno porte, localizada na Grande São Paulo, tendo três empregados, supervisionados pelo proprietário, e com produtividade e lucratividade médias.

Seguindo os indicadores de QVT apresentados por Limongi-França (2007), como citado em Equipe FIA da Pesquisa Melhores Empresas (2019), e Arellano e LimongiFrança (2013), foram sondadas várias práticas de QVT, conforme Apêndice A, e os resultados obtidos estão relatados na Tabela 2, a seguir: 
Tabela 2 - Indicadores de QVT ausentes e presentes na empresa pesquisada.

\begin{tabular}{|c|c|}
\hline Indicadores de QVT ausentes & $\begin{array}{l}\text { Indicadores de } \\
\text { QVT presentes }\end{array}$ \\
\hline $\begin{array}{l}\text { Os empregados da linha de frente são tratados pelo chefe como sendo } \\
\text { facilmente substituíveis; trabalham sob pressão e com receio de serem } \\
\text { demitidos; sentem-se mal tratados; o clima de trabalho não é agradável; sentem- } \\
\text { se subutilizados; executam trabalhos de baixa complexidade, por isso são } \\
\text { poucos os requisitos exigidos para a seleção de novos empregados; para não } \\
\text { cometer erros, esses atendentes são obrigados a agir de acordo com manuais e } \\
\text { regras que bloqueiam a inovação; o treinamento que recebem se restringe à } \\
\text { operação do serviço, não focando boas práticas de atendimento ao cliente; não } \\
\text { têm perspectivas de carreira; são obrigados a desempenhar mais tarefas do que } \\
\text { o combinado pela remuneração e cargo; não recebem por horas extras; não têm } \\
\text { banco de horas acumuladas; a política de remuneração nunca é revista; não } \\
\text { recebem bonificações por metas alcançadas; não recebem remuneração } \\
\text { compatível com o mercado; não sobem de cargos ou obtém aumentos na } \\
\text { remuneração pelo tempo de casa ou pelo desempenho apresentado; não têm } \\
\text { autonomia para resolver questões com os clientes; não são estimulados a } \\
\text { desenvolver seus potenciais e nem novas competências; somente o chefe tem o } \\
\text { poder para decidir; são estimulados a vender mais, independentemente da } \\
\text { necessidade do cliente e, se o cliente sai sem comprar, é chamado a atenção; } \\
\text { não há incentivo ao equilíbrio entre o tempo dedicado ao trabalho e o tempo } \\
\text { dedicado à família e aos amigos. }\end{array}$ & $\begin{array}{lr}\text { A empresa investe } \\
\text { na saúde } \\
\text { segurança } \\
\text { trabalho no } \\
\text { empregados. }\end{array}$ \\
\hline
\end{tabular}

Fonte: os autores

A análise da Tabela 2 revela que, na empresa pesquisada, há apenas uma prática voltada para a Qualidade de Vida no Trabalho: o investimento na saúde e segurança dos empregados. No entanto, ainda que não haja investimento nas dimensões psicológica, social e organizacional, conforme Arellano e Limongi-França (2013), o turnover e o absenteísmo são baixos, e o tempo médio de permanência dos empregados na empresa é superior a 18 meses. Mesmo trabalhando em um ambiente não agradável, os empregados amedrontados/desmotivados/insatisfeitos produzem serviços de qualidade, cativando e gerando a fidelização do cliente, e nunca sabotam a empresa, transferindo o descontentamento ao atender o cliente.

A despeito de a empresa pesquisada gerir seus empregados com práticas que caracterizam o ciclo de fracasso (Tabela 1), a produtividade e a lucratividade localiza-se no ciclo da mediocridade, com margens médias de produtividade e lucratividade.

Assim, este estudo, propondo-se a verificar se a produtividade e a lucratividade da empresa pesquisada são consequência do investimento que ela faz em programas de QVT, demonstrou que essa consequência não é exclusiva da manutenção dos programas de QVT, 


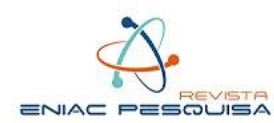

porque se assim fosse, como a empresa tem apenas uma ação de QVT, suas margens seriam baixas e não médias como foram encontradas na pesquisa de campo.

Com base nesse resultado, é possível concluir que a produtividade e lucratividade dessa empresa não são consequência exclusiva do investimento em programas de QVT, porque outras variáveis podem interferir nesse processo, tais como: liderança coercitiva, imaturidade e pouco preparo dos empregados para se colocarem no mercado de trabalho, dentre outros fatores.

\section{CONSIDERAÇÕES FINAIS}

Este estudo permite considerar que os resultados de fracasso e/ou mediocridade são decorrência da relação de trabalho entre empregador e empregado. Uma relação de excelência entre eles produz resultados de excelência.

O estudo mostrou que o empregado, por mais desmotivado que esteja, nem sempre transferirá sua insatisfação ao cliente, podendo até cativá-lo, porém deixando arestas a serem aparadas.

As empresas que atuam com modelos de gestão modernos estão cada vez mais investindo na qualidade de vida de seus empregados como agente motivador para a vantagem competitiva das empresas. Por outro lado, as empresas que não o fazem, permanecerão estagnadas, até cair na obsolescência, e no ciclo do fracasso.

Um estudo futuro poderia dedicar-se a ouvir os empregados que trabalham em ambientes ruins, e perguntar por que continuam trabalhando nessa empresa.

Com os resultados da Tabela 2, podemos concluir que o objetivo que norteou esta pesquisa foi atingido, pois ficou demonstrado que a produtividade e a lucratividade da empresa pesquisada não são consequência exclusiva do investimento em programas de QVT, porque se assim fosse, seus resultados seriam baixos (Tabela 1), porque a empresa não investe em programas de QVT. Porém, como suas margens de produtividade e de lucratividade são médias, é possível inferir que há outras variáveis interferindo nessa relação. 


\section{REFERÊNCIAS}

Alves, F., Lins, J. (2013) Temas Empresariais Capital humano A gestão de pessoas num mundo em transformação (p. 12). Recuperado em 19 de Setembro, 2019 de https://www.pwc.com.br/pt/publicacoes/revista-temas-empresariais/assets/capitalhumano-13.pdf

Arellano, E. B.; Limongi-França, A. C.(2013). Análise crítica dos indicadores dos programas de qualidade de vida no trabalho no Brasil. O Mundo da Saúde (CUSC. Impresso), v. 37, p. 141-151.

Assis, R. V. de, (2009), Dinâmica organizacional da empresa moderna: as relações jurídicas de trabalho frente às transformações político-econômicas do século XXI Piracicaba Recuperado em 03 de Novembro, 2019 de https://www.unimep.br/phpg/bibdig/pdfs/2006/RGCNTLPJMVJB.pdf

Chiavenato, Idalberto. (1999). Gestão de pessoal: o novo papel dos recursos humanos nas organizações. $13^{\mathrm{a}} \mathrm{Ed}$. Rio de Janeiro: Campus.

Dutra, J. de S.; Dutra, T. A. \& Dutra, G.A. (2017). Gestão de Pessoas: realidade atual e desafios futuros. São Paulo: Atlas.

Equipe FIA Lucas, A.; Tumelero, C.; Veloso, E.: Vicentin, R.; Wahnon, V. \& Amorim, W. (2019). As 10 Melhores Empresas para se Trabalhar no Brasil e a Qualidade de Vida no Trabalho. Revista da Universidade Presbiteriana Mackenzie, 1-16

Fernandes, F. do C., Rosito, G. A., Teixeira, M. M. S., Mota, G. A., Patrício, J. da S., Moraes, G. C. de; Kiorsak, V. V. (2006) Brasília: Revista Brasileira de Inteligência.

Freire, M. G.. (2013) Qualidade de Vida no Trabalho. Brasília: UNICEUB.

Kliksberg, B. (1992) A Gerência No Final Do Século XX. Artigo recebido em dez. 1991 e aceito em maio 1992. Rio de Janeiro.

Lobo, A. Qualidade e Produtividade. (2003) Recuperado em 25 de Fevereiro, 2020 de http://repositorios.inmetro.gov.br/bitstream/10926/760/1/2003_AlfredoLobo.pdf

Lovelock, C. ; Hemzo, M.A. \& Wirtz, M. A. H. (2011) Marketing de serviços: pessoas, tecnologia e estratégia. (7 ed.). São Paulo: Pearson Prentice Hall. Tradução Sônia Midori Yamamoto.

Macedo, M. de M., Gestão da Produtividade de Nas Empresas. (2012) Revista Organização Sistêmica. Vol 1. Recuperado em 24 de Fevereiro, 2020 de https://www.uninter.com/revistaorganizacaosistemica/index.php/organizacaoSistemica/ar $\underline{\text { ticle/viewFile/65/39 }}$

Machline, C. (1985). Planejamento e controle de produção na indústria nacional de bens de equipamento. Rev. adm. Empres 25(2): 5-28.

Marques, J. R., Relações Humanas no Trabalho - Definidoras de Sucesso ou Fracasso de uma Empresa. (2019). Recuperado em 29 de Setembro, 2019 de: https://www.ibccoaching.com.br/portal/relacoes-humanas-no-trabalho-definidorassucesso-ou-fracasso-empresal 
Martins, M. A (2006). Avaliação de desempenho empresarial como ferramenta para agregar valor ao negócio. Revista Com Texto, Porto Alegre, v. 6, n. 10, 2º semestre. 2006.

Massi, M., Pereira, K., Santana, R., Gonçalves, S., Souza, V., Silva, V., \& Silva, W. (2010). Investimentos em recursos humanos em dez micro e pequenas empresas de Osasco e região. Revista Científica Hermes - FIPEN, 3. doi:http://dx.doi.org/10.21710/rch.v3i0.32

Monteiro, S.; Martins, L. L. B. M.; Alves, R. A.; Paulista, P. H. (2015). Gestão de Pessoas: A valorização do Humano como um Diferencial para o Êxito de uma Organização. $X X X V$ Enegep - Encontro Nacional de Engenharia de Produção.

Moretti, S., (?) Qualidade de Vida no Trabalho X Auto-Realização Humana. Instituto Catarinense de Pós Graduação. Recuperado em 29 de Setembro, 2019 de: http://www.ergonomia.ufpr.br/PB\%20qvt\%20realiz\%20humana.pdf

Reggiani, G. B., Prada, N., Figueiredo, d. F. Gestão da produtividade: metodologia aplicada a uma indústria de bebidas. Xii simpep, (2005). Recuperado em 05 de novembro, 2019 de www.simpep.feb.unesp.br.

Rocha, R. A. da, Guilhon, P. de T. (1997?), Intrapreneur: Multiplicador De Novos Negócios Recuperado em 29 de Setembro, 2019 de http://www.abepro.org.br/biblioteca/ENEGEP1997_T7302.PDF

Santana, L. D., Gosling, M. S., "P” de Pessoas em Foco: Indicadores Epidemiológicos e QVT. Artigo submetido em Setembro de 2017 e aceito em dezembro de 2017.

Schlesinger, L. A. and Heskett, J. L. (1991) Breaking the Cycle of Failure in Services, Sloan Management Review, vol. 32, no. 3, Spring, pp. 17-28.

Schenatto, F. J. A,, Lezana, Á. G. R. (2001) O Intraempreendedor Como Agente De Mudança Nas Instituições Públicas Federais De Educação Superior Paraná CEFET-PR $\begin{array}{llllll}\text { Recuperado em } & 07 & \text { de } & \text { Novembro, } & 2019 & \text { de }\end{array}$ http://www.abenge.org.br/cobenge/arquivos/18/trabalhos/EMP001.pdf

Secco, W. (2014). Principais fatores que afetam a produtividade nas indústrias de Pato Branco. Monografia. Universidade Tecnológica Federal do Paraná - UTFPR - Câmpus de Pato Branco. Paraná. Brasil. Recuperado em 29 de Setembro, 2019 de http://repositorio.roca.utfpr.edu.br/jspui/bitstream/1/3368/1/PB_EGCF_IX_2014_17.pdf

Serva, M. (1997) Racionalidade substantiva demonstrada na prática administrativa. Revista de Administração de empresas, São Paulo, v.37, n.2: 18-30.

Sink, D. Scott; Tuttle, Thomas C. (1993) Planejamento e medição para performance. Rio de Janeiro: Quality Mark, 1993

Sucesso, E. de P. B., (1998) Trabalho e Qualidade de Vida. Rio de Janeiro: Qualitymark Editora e Dunya Editora.

Vasconcelos, A. F., Qualidade de Vida no Trabalho: Origem, Evolução e Perspectivas (2001) São Paulo. Caderno de Pesquisas em Administração. Recuperado em: 09 de Novembro. $2019 \quad$ de: $\quad$ http://www.luzimarteixeira.com.br/wpcontent/uploads/2009/06/qualidade-de-vida-no-trabalho-origem.pdf 
APÊNDICE A

Caracterização da empresa: Comércio

Localização:

Número de empregados:

Cartela de clientes ( $\mathrm{n}^{\circ}$. Aproximado):

\begin{tabular}{lll}
\hline Produtividade: ( ) Baixa & ( ) Média & ( ) Alta \\
\hline Lucratividade: ( ) Baixa & ( ) Média & ( ) Alta
\end{tabular}

Data de realização da pesquisa:

Cargo/posição do entrevistado:

QUESTÕES

1. $\quad$ Os empregados da linha de frente são facilmente substituíveis?

2. Os empregados da linha de frente sentem-se subutilizados?

3. Os empregados da linha de frente executam trabalhos de baixa complexidade, por isso são poucos os requisitos exigidos para a seleção de novos empregados?

4. Para não cometer erros, os empregados da linha de frente são obrigados a agir de acordo com manuais e regras que bloqueiam a inovação?

5. Qualquer que seja o desempenho, os empregados sobem de cargos ou obtém aumentos na remuneração pelo tempo de casa?

6. Os empregados desmotivados/insatisfeitos sabotam a empresa, transferindo o descontentamento ao atender o cliente, afugentando-os e manchando a imagem da empresa?

7. $\quad$ Os índices de turnover e de absenteísmo são baixos?

8. $\quad$ Os empregados da linha de frente recebem remuneração compatível com o mercado?

9. Os empregados da linha de frente têm autonomia para resolver questões com os clientes?

10. O tempo médio de permanência dos empregados na empresa é de até 18 meses?

11. O treinamento oferecido para os empregados da linha de frente se restringe à operação do serviço?

12. O treinamento para os empregados da linha de frente foca também as boas práticas de atendimento ao cliente?

13. Somente os chefes têm o poder para decidir?

14. O lucro da empresa é comprimido a uma pequena margem?

$15 . \quad$ Os empregados são bem tratados pela empresa?

16. A empresa investe na saúde e segurança no trabalho dos empregados? 


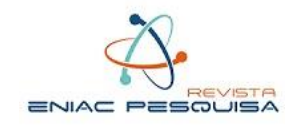

\begin{tabular}{|c|c|c|}
\hline 17. & $\begin{array}{l}\text { A empresa oferece aos empregados da linha de frente perspectivas de } \\
\text { carreira? }\end{array}$ & \\
\hline 18. & $\begin{array}{l}\text { A empresa incentiva o equilíbrio entre o tempo dedicado ao trabalho } \\
\text { e o tempo dedicado à família e aos amigos? }\end{array}$ & \\
\hline 19. & A empresa revisa periodicamente a política de remuneração? & \\
\hline 20. & A empresa prioriza o desenvolvimento do potencial humano? & \\
\hline 21. & $\begin{array}{l}\text { A empresa, constantemente, incentiva os empregados a } \\
\text { desenvolverem novas competências? }\end{array}$ & \\
\hline 22. & $\begin{array}{l}\text { Os empregados produzem serviços de qualidade, cativando e gerando } \\
\text { a fidelização do cliente? (Mesmo não sendo bem tratados) }\end{array}$ & \\
\hline 23. & O clima de trabalho é sempre muito agradável? & \\
\hline 24. & A produtividade dos empregados da linha de frente é sempre alta? & \\
\hline 25. & Os funcionários trabalham sob pressão? & \\
\hline 26. & Os funcionários trabalham sempre com receio de serem demitidos? & \\
\hline 27. & $\begin{array}{l}\text { A empresa estimula o colaborador a vender mais, independente da } \\
\text { necessidade do cliente? }\end{array}$ & \\
\hline 28. & $\begin{array}{l}\text { Se o cliente sai sem comprar nada, o funcionário "é chamado a } \\
\text { atenção"? }\end{array}$ & \\
\hline 29. & A empresa fornece bonificações por metas alcançadas? & \\
\hline 30. & $\begin{array}{l}\text { A empresa obriga o colaborador a desempenhar mais tarefas do que o } \\
\text { combinado pela remuneração e cargo? }\end{array}$ & \\
\hline 31. & $\begin{array}{l}\text { A empresa paga por horas extras/banco de horas acumulados pelo } \\
\text { funcionário? }\end{array}$ & \\
\hline
\end{tabular}

